\title{
Comparative Study of Regulations of Devices for Aesthetic Purposes: US, European Union, China, and Taiwan
}

\author{
Mei-Fen Chen ${ }^{1}$. Cheng-Lun Tsai ${ }^{2}$ Y Yung-Hsin Chen ${ }^{3}$. Cheng-Ning Wu ${ }^{4} \cdot$ Ching Chou ${ }^{4}$. Chia-Hung Chien ${ }^{4}$. \\ Pei-Weng Tu${ }^{4} \cdot$ Tsair Kao $^{3} \cdot$ Kang-Ping Lin ${ }^{1}$
}

Received: 26 April 2019 / Accepted: 17 July 2019 / Published online: 27 August 2019

(c) The Author(s) 2019

\begin{abstract}
Purpose The aim of this study is to examine how aesthetic devices are defined and managed. Regulation discrepancies between clinical use and home use in four regions are also described.

Methods The official websites and databases of US, European, Chinese, and Taiwanese authorities were used to collect regulation information for aesthetic devices. Moreover, the regulations for eight aesthetic products, four used in clinics by experts and four used at home by lay people, were compared.

Results The results show that the principle of operation and intended use are key points for determining whether an aesthetic device is a medical device (MD). Although the term "aesthetic" is not included in the MD definition, most aesthetic devices are regulated as MDs by the four regional authorities based on the devices' technical specifications and intended use, especially for high-risk devices and high-end products. For home-use aesthetic devices, the control measures also depend on function and intended use, but different authorities have different acceptance ranges. Manufacturers should pay more attention to regulation requirements in difference regions before putting devices on the market.

Conclusion With the fast growth of aesthetic devices, government authorities need to make regulations to keep up with new products. Determining whether an aesthetic product is an MD on the basis of its risk could be a practical option for administrators. This study evaluated the regulation of aesthetic devices as MDs in the US, European Union, China, and Taiwan, and provides important information for further policy and regulation development.
\end{abstract}

Keywords Aesthetic device $\cdot$ Medical device $\cdot$ Regulation

\section{Introduction}

The demand for aesthetic surgery has increased significantly in recent years. According to statistics provided by the International Society of Aesthetic Plastic Surgery (ISAPA), over 10 million surgical procedures were performed on average per year from 2013 to 2016, and nearly 12 million

Kang-Ping Lin

kplin@cycu.edu.tw

1 Electrical Engineering Department of Chung Yuan Christian University, Taoyuan 32023, Taiwan, ROC

2 Biomedical Engineering Department of Chung Yuan Christian University, Taoyuan 32023, Taiwan, ROC

3 Technology Translation Center for Medical Device of Chung Yuan Christian University, Taoyuan 32023, Taiwan, ROC

4 Food and Drug Administration, Ministry of Health and Welfare, Taipei 11561, Taiwan, ROC nonsurgical procedures were performed in the same period [1-5]. The latest report by ISAPA showed that the total number of procedures grew by $9 \%$ from 2015 to 2016 . A report by Grand View Research Inc. showed that the global aesthetic medicine market is expected to reach USD 11.9 billion by 2022 [6]. The global aesthetic medicine market is thus booming, and related industries have been developed, especially devices for aesthetic purposes. Various types of aesthetic products are available in the market, such as decorative contact lenses, intense pulsed light facial rejuvenation devices, laser hair removal devices, radio-frequency wrinkle reduction devices, and electrical facial devices, for both clinical and home use. How to manage and control such devices has become a challenge for regulatory authorities.

High-risk devices, such as dermal fills, breast implants, and laser equipment, are regulated as medical devices (MDs). However, there are no consistent global rules for managing aesthetic devices that can be followed by 
manufacturers. Furthermore, due to the growth of the beauty market, an increasing number of medical technologies is being applied to the development of home-use aesthetic products, which have a wide variety of functions and can be easily purchased by the general public. How to supervise and manage home-use aesthetic products while taking into consideration the safety of consumers and the development of the aesthetic industry is a serious issue for MD and cosmetic authorities. Therefore, it is necessary to examine existing aesthetic product management information in different regions for future aesthetic device policy and regulation development.

This study evaluated four important plastic surgery markets, namely the US, EU, China, and Taiwan, to examine their regulation policies regarding aesthetic devices to determine the regulatory framework for aesthetic devices. This study also attempts to discern regulation differences by examining eight different aesthetic products, four used in clinics by experts and four used at home by lay people. The aim of this study is to draw attention to aesthetic device management, especially for home-use products, by investigating current regulation mechanisms, to suggest reference points that will be helpful for enhancing device use safety, and to provide valuable information for authorities and industry.

\section{Methods}

Regulations in the US, EU, China, and Taiwan on aesthetic devices were examined. The data collection and analysis step of this study is shown in Fig. 1.

\subsection{Collection of Regulation Information on Aesthetic Devices for Four Regions}

High-risk aesthetic devices are regulated as MDs. Information on how aesthetic devices are defined as MDs and complementary control measures was collected using the search terms "aesthetic" and "aesthetic purpose" in the medical regulation and product classification databases and lists for the four regions. Since the US, China, and Taiwan MD authorities have official websites and the EU has an official website for finding law information, these were the major sources for data collection in this study.
Fig. 1 Data collection and analysis step used in this study






\subsection{Collection of Regulation Information for Clinical Use and Home-Use Aesthetic Products for Four Regions}

Aesthetic devices are usually based on one of four principles of operation: heating/cooling, ultrasound, optics, and electricity. In this step, four clinical use devices and four home-use devices based on the principle of operation were respectively selected. For each principle of operation, one high-end product and one personal use product were selected. The regulations for these eight products (Table 1) were obtained for the four regions. The category and classification were the primarily information collected for later comparison and analysis.

\subsection{Information Analysis and Comparison}

In order to clarify the regulation differences among the four regions, information on aesthetic devices was analyzed and compiled based on region. Then, the regulation information for the eight selected products (product description, classification, code, and MD status) was analyzed. Finally, the analyzed regulation information for the four regions was compared.

\subsection{Results and Discussion}

The results of the aesthetic device definition analysis for the four regions and a comparison of regulations for highend and home-use products are presented in this section. A discussion is also given.

The regulation information was obtained from the official websites and databases of the United States Food and Drug Administration (FDA, https://www.fda.gov), European Commission (EC, https://ec.europa.eu), China Food and Drug Administration (CFDA, http://samr.cfda.gov.cn), and Taiwan Food and Drug Administration (TFDA, https:// www.fda.gov.tw).

\section{Results}

\subsection{Regulation Summaries of Aesthetic Devices for Four Regions}

\subsubsection{United States}

In the US, the legal authority that regulates MDs is the FDA. Any product that is labeled, promoted, or used in a manner that meets the requirements in section 201(h) of the Federal Food Drug \& Cosmetic (FD\&C) Act is regulated by the FDA. In section 201(h), the definition of an MD does not include the terms "aesthetic" or "aesthetic purpose". However, at least 14 devices (material not included) classified in the Center for Devices and Radiological Health (CDRH) classification database have descriptions that include "aesthetic use" (Table 2), such as electrosurgical coagulation for aesthetic use (product code: ONQ) and laser for disruption of adipocyte cells for aesthetic use (product code: PKT) [7]. Aesthetic devices are not limited to the 14 product codes listed in Table 2. As long as a device's working principle and intended use conform with the information listed in the CDRH product classification database, then the device is regulated as an MD. If a device is not covered by the scope of MDs, the intended use and label should not include anything medicine-related. Cosmetic use is also regulated by the FDA but under different regulations. Manufacturers should check product classification and regulation rules based on a product's characteristics when launching a product. Table 3 summaries the aesthetic device regulations for the US, EU, China, and Taiwan.

Table 1 Eight aesthetic devices selected in this study based on four principles of operation

\begin{tabular}{lll}
\hline Principle of operation & Clinic use product name and description & Home-use product name and description \\
\hline Heating/cooling & $\begin{array}{l}\text { Skin cooling system for lipolysis } \\
\text { Description: A non-invasive body contouring treatment } \\
\text { used to reduce fat cell volume by freezing }\end{array}$ & $\begin{array}{l}\text { Hot/cool facial massager } \\
\text { Description: A device for facial skin care. It relaxes skin and } \\
\text { Ultrascelerates blood circulation }\end{array}$ \\
& $\begin{array}{c}\text { Focused ultrasound system for lipolysis } \\
\text { Description: The system delivers high-intensity focused }\end{array}$ & $\begin{array}{l}\text { Ultrasonic facial massager } \\
\text { Description: To deliver high-frequency waves to user skin }\end{array}$ \\
& ultrasound energy to non-invasively disrupt subcutane- & \\
ous adipose tissue & \\
Optics & Powered laser surgical instrument & Light-based hair removal \\
& Description: Removes unwanted brown spots, sun freckles,, & Description: Uses light or intense pulsed light to slow down \\
& or tattoos from user's skin & hair growth by damaging hair follicles \\
Electricity & Radio-frequency energy system & Electric facial massager \\
& Description: Delivers radio-frequency energy deep into & Description: Uses micro-current to enhance results of skin- \\
& dermal tissues for skin tightening and wrinkle reduction & care products and improve metabolism
\end{tabular}


Table 2 Product code of devices with aesthetic purpose listed in FDA medical device classification database

\begin{tabular}{|c|c|c|}
\hline & Product code & Device \\
\hline 1 & GEX & Powered laser surgical instrument \\
\hline 2 & NFO & $\begin{array}{l}\text { Stimulator, transcutaneous electrical, aesthetic } \\
\text { purposes }\end{array}$ \\
\hline 3 & NYX & $\begin{array}{l}\text { Stimulator, electrical, transcutaneous, with limited } \\
\text { output, for aesthetic purposes }\end{array}$ \\
\hline 4 & NYZ & $\begin{array}{l}\text { Stimulator, muscle, powered, with limited output, for } \\
\text { muscle conditioning }\end{array}$ \\
\hline
\end{tabular}

5 OHV Focused ultrasound for tissue heat or mechanical cel- 2 lular disruption

6 OLI

7 ONE

Fat reducing low level laser

Powered light based non-laser surgical instrument

$8 \mathrm{ONF}$

9 ONG

10 ONQ

11 OOK

12 PAY

13 PKT

14 QAI
Powered light based non-laser surgical instrument with thermal effect

Powered laser surgical instrument with microbeaml fractional output

Electrosurgical coagulation for aesthetic

Dermal cooling pack/vacuum/massager

Over-the-counter radiofrequency coagulation device for wrinkle reduction

Laser for disruption of adipocyte cells for aesthetic use

Powered microneedle device
Device class Regulation description

2

2

2

Laser surgical instrument for use in general and plastic surgery and in dermatology

Transcutaneous electrical nerve stimulator for pain relief

Transcutaneous electrical nerve stimulator for pain relief

Powered muscle stimulator. Not intended to be used for medical purposes (e.g., rehabilitation), for aesthetic purposes (e.g., changing the physical appearance of the muscle or body), or for the purpose of improving athletic performance

Focused ultrasound stimulator system for aesthetic use

Low level laser system for aesthetic use

Laser surgical instrument for use in general and plastic surgery and in dermatology

2 Laser surgical instrument for use in general and plastic surgery and in dermatology

Laser surgical instrument for use in general and plastic surgery and in dermatology

Electrosurgical cutting and coagulation device and accessories

Contact cooling system for aesthetic use

Electrosurgical device for over-the-counter aesthetic use

Low level laser system for aesthetic use

A powered microneedle device is a device using one or more needles to mechanically puncture and injure skin tissue for aesthetic use

Table 3 Summary of aesthetic devices controlled by medical device regulations in the US, EU, China, and Taiwan

Region Regulation

US - FDA has specialized product codes for aesthetic devices in CDRH database

- Devices are regulated by MD regulation if their function complies with the description in MD product classification

- Products that are not MDs cannot make any medical claim on labels and intended use

Europe - Certain product groups listed in Annex XVI are regulated by MDR, including aesthetic or other implantable or invasive products such as non-corrective contact lenses, equipment for liposuction, and hair removal lasers

- For unclear products, manufacturers should refer to guidance documents such as the manual on borderline products and classification provided by the European Commission. Some borderline products need to be confirm case by case depending on their characteristics

- Cosmetic products should not make any explicit or implicit claims related to prevention or treatment

China - The term "aesthetic purpose" is not included in the CFDA MD definition

- CFDA does not have any specialized product codes for aesthetic devices in MD list

- Any device that conforms to the product description in MD list is regulated as an MD

- CFDA announces notices of product definitions as supplementary material for defining whether a product is regulated as an MD

Taiwan - TFDA does not have any specialized product codes for aesthetic devices in the MD classification database

- Devices are regulated by MD regulation if their function complies with the description in MD product classification

- Aesthetic device that claims a medical intention or treatment effects, such as skin improvement, reducing wrinkles, or to stimulate collagen or cell production, needs to follow MD regulation (e.g. classification number I.0008-Transcutaneous skin stimulator) 


\subsubsection{European Union}

The latest regulations on MDs in EU are the Medical Devices Regulation (MDR), Regulation 2017/745, published on 5 April, 2017, and entered into force on 25 May, 2017 [8]. The regulation, in an effort to reshape and improve essential health and safety practices and guidelines, has widened the scope not only of aesthetic products but also non-medical devices. Six groups of products listed in the MDR (Article 1, Annex XVI) without an intended medical purpose are listed below.

(1) Contact lenses or other items intended to be introduced into or onto the eye.

(2) Products intended to be totally or partially introduced into the human body through surgically invasive means for the purpose of modifying the anatomy or fixation of body parts with the exception of tattooing products and piercings.

(3) Substances, combinations of substances, or items intended to be used for facial or other dermal or mucous membrane filling by subcutaneous, submucous or intradermal injection or other introduction, excluding those for tattooing.

(4) Equipment intended to be used to reduce, remove, or destroy adipose tissue, such as equipment for liposuction, lipolysis, or lipoplasty.

(5) High-intensity electromagnetic radiation (e.g., infrared, visible light, and ultraviolet) emitting equipment intended for use on the human body, including coherent and non-coherent sources, monochromatic and broad spectrum, such as lasers and intense pulsed light equipment, for skin resurfacing, tattoo, or hair removal or other skin treatment.

(6) Equipment intended for brain stimulation that apply electrical currents or magnetic or electromagnetic fields that penetrate the cranium to modify neuronal activity in the brain.

Before the United Kingdom left the EU, the Medicines and Healthcare products Regulatory Agency (MHRA), an executive agency of the Department of Health and Social Care in the UK, provided guidance to clarify that devices without medical purposes are not considered as MDs [9-11]. This means that even high-risk products were not officially regulated as MDs; they were only listed in a proposal by the European Commission until the MDR entered into force in 2017. Now, high-risk aesthetic products are included in the MDR for user safety. Moreover, for borderline products, which are not clearly cosmetic or medical products, the European Commission evaluates them based on risk. For example, for products delivered via iontophoresis or similar principles, a case-by-case evaluation of all characteristics of the product is necessary. If the use of a device only affects the skin epidermis, then the product is cosmetic; if the use of a device induces a deeper penetration of certain ingredients, then the product is not cosmetic [12].

\subsubsection{China}

The CFDA is the legal authority that regulates MDs in China. Their definition of an MD is [13]:

Any instrument, apparatus, appliance, material, in vitro diagnostic reagents and calibration substances and other similar substances and related articles, including the needed computer software. Its main effectiveness is achieved via physics ways and so on. It does not achieve its principal action in or on the human body by means of pharmacology, immunology or metabolism, but which may be assisted in its function by such means; the use of which is to achieve the following intended objectives:

- Diagnosis, prevention, monitoring, treatment or alleviation of disease;

- Diagnosis, monitoring, treatment, alleviation of or compensation for an injury or handicap conditions;

- Investigation, replacement or modification for anatomy or a physiological process;

- Life support or maintenance;

- Control of conception;

- Offer information for medical or diagnosis purpose via inspecting the human samples.

According to an announcement by the CFDA, a new medical device classification catalog (MD List) was implemented on August 1, 2018 [14]. For CFDA registration applications submitted on or after the August 2018 deadline, the new catalog will fully apply. Compared to the existing MD list (issued in 2002), the new catalogue provides a more clear and complete structure, and has the follow major modifications:

(1) Reduces the number of device categories from 43 to 22 based on the MDs' functions and clinical uses.

(2) Provides clearer guidance and product examples that enable companies to determine the level of regulatory control. For example, each catalogue of the new MD List contains a primary type, sub-type, device description, intended use, device examples, and classifications for Classes I, II, and III. It also includes 6609 devices in the device example column, while the existing MD list offers only 1008 example devices.

(3) Downgrades the classification of 40 devices to Class II (e.g., infusion pumps for surgical instruments) or Class I (e.g., plate washers). It upgrades the classification of 
certain types of devices to Class III (e.g., alcohol swabs and active breathing coordinators).

From the MD definition above, if a product does not have a medical purpose, it is not considered as an MD. Furthermore, for the new MD list, there were no results for the terms "aesthetic" and "aesthetic purpose", even in device descriptions, intended use, and device examples. However, highrisk aesthetic devices are regulated based on the device's working theory. For example, a facial skin care device or hair removal device that uses intense pulsed light (IPL) is regulated under the code 09-09-04-Intense pulsed light therapy equipment $[14,15]$.

\subsubsection{Taiwan}

The TFDA is the legal authority that regulates MDs in Taiwan. The Pharmaceutical Affairs Law (PAL) regulates the manufacturing, importation, and sale of MDs and pharmaceuticals in Taiwan. According to PAL Article 13 [16], an MD is:

The term "medical devices" as refer to instruments, machines, apparatus, and their accessories, fittings and parts which are used in diagnosing, curing, alleviating, or directly preventing the diseases of human beings, or which may affect the body structure or functions of human beings. The central competent health authority shall establish Regulations Governing the Management of Medical Devices in regards to its scope, classification, management, and other matters in accordance with practical needs.

Same as the other regions, the definition of an MD does not include the terms "aesthetic" or "aesthetic purpose". However, for protecting customer safety and keeping up with the product development. TFDA updated MD classification database irregularly. According to the latest database update announced on July 25, 2017, new 27 device categories had been added on the database and 18 device categories had been amended. Which updates associated with aesthetic product included [17]:

(1) Added new device category I.0008-Transcutaneous skin stimulator. The identification of this device is to apply energy (e.g., electrical current, optical energy or ultrasound energy) on a patient's skin up to dermal or subdermal layers to modify skin appearance (e.g., skin tightening, toning, lifting or reducing wrinkles) or to stimulate collagen or cell production. Base on the identification of I.0008, many facial toning devices or skin care devices based on micro-current or ultrasound technology need to get approval before them be distributed on Taiwan's market [18].

(2) Amended the identification of device category I.0001High density subcutaneous electrical wrinkle reduc- tion device as a device applying an electrical current to electrodes on a patient's skin up to subdermal or muscle layers for reducing body wrinkles and connective tissue swelling by physical action. This device applies high density electrical current to stimulate collagen and elastin production by heating tissues in the deep layers of the skin [19].

(3) Adjusted the class of device category O.5525-Iontophoresis device from class III to class II. The iontophoresis device uses a current to introduce ions of drugs or nondrug solutions into the patient's body for achieving specific medical purposes. According to the identification, an ionic facial device which claim with ionic treatment function need to follow the MD regulation as Class II in Taiwan [20].

\subsection{Regulation Comparison for Clinical Use and Home-Use Aesthetic Products Based on the Four Principles of Operation and Four Regions}

The control features under MD regulation of the eight selected products in different regions are highlighted in Table 4 . The regulations are described below in detail.

\subsubsection{Heating/Cooling}

A skin cooling system for lipolysis is a non-invasive treatment for reducing fat cell volume by freezing. Lipolysis or the reduction of adipose tissue is an important market in plastic surgery. Different kinds of technology are applied in this market. A skin cooling lipolysis system uses high energy delivery to reduce adipose tissue. This system is regulated as an MD and is classified as Class II or III in all four regions.

A hot/cool facial massager is a device for personal facial skin care. It relaxes skin and accelerates blood circulation. Generally, the device's maximum temperature should be not over $42{ }^{\circ} \mathrm{C}$ and not below $6{ }^{\circ} \mathrm{C}$. This study did not find a corresponding product code for the hot/cool facial massager in the CDRH product classification database based on the temperature change and massage function. In EU, the hot/ cool facial massager may be classified as a cosmetic product according to the borderline working manual [12]. For the CFDA, based on the working theory, this device is not regulated as an MD. Furthermore, if this product does not claim any medical purposes, the TFDA would not treat this device as an MD in Taiwan.

\subsubsection{Ultrasound}

A focused ultrasound system for lipolysis delivers highintensity focused ultrasound energy to non-invasively disrupt subcutaneous adipose tissue. In China, this device 


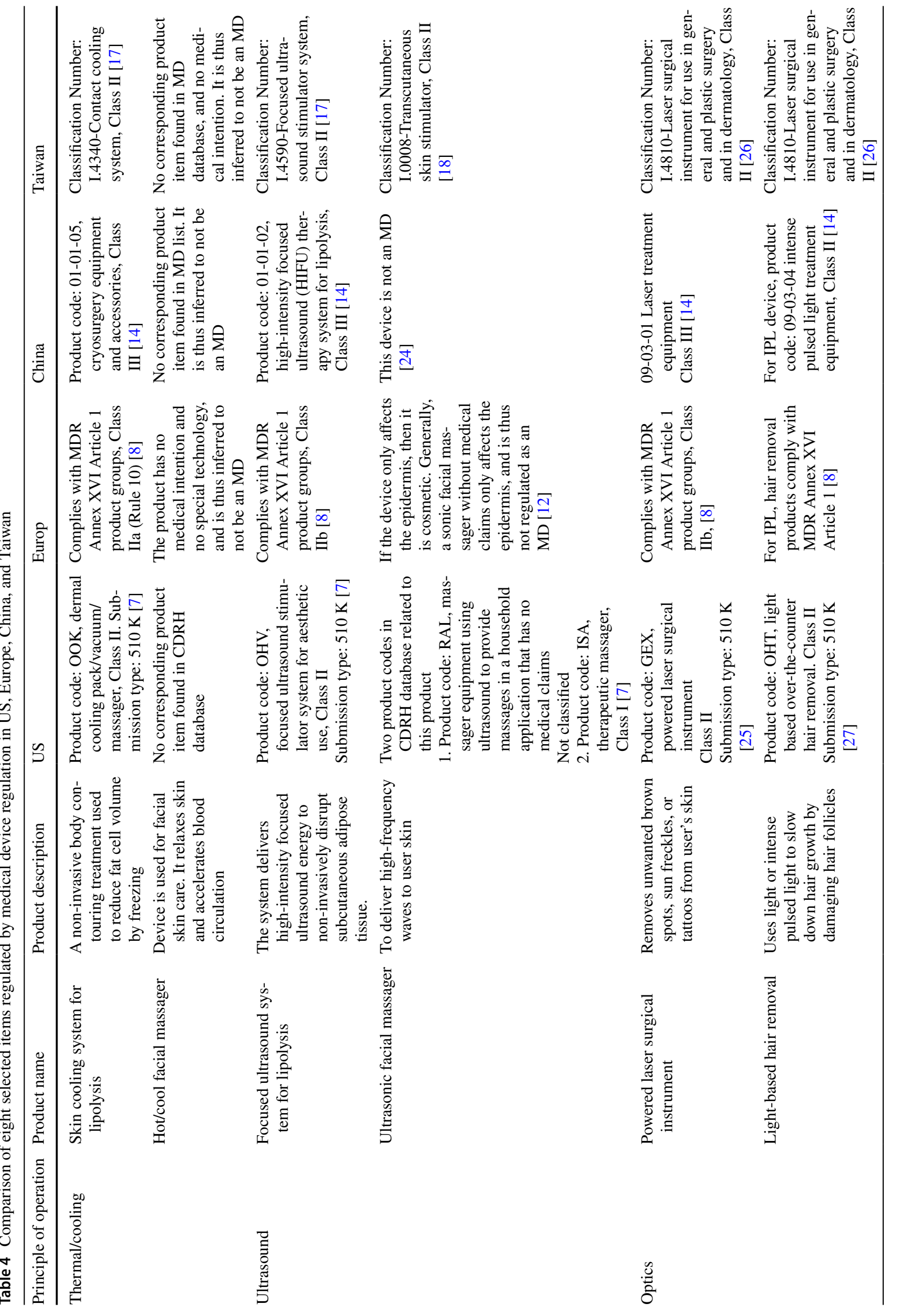




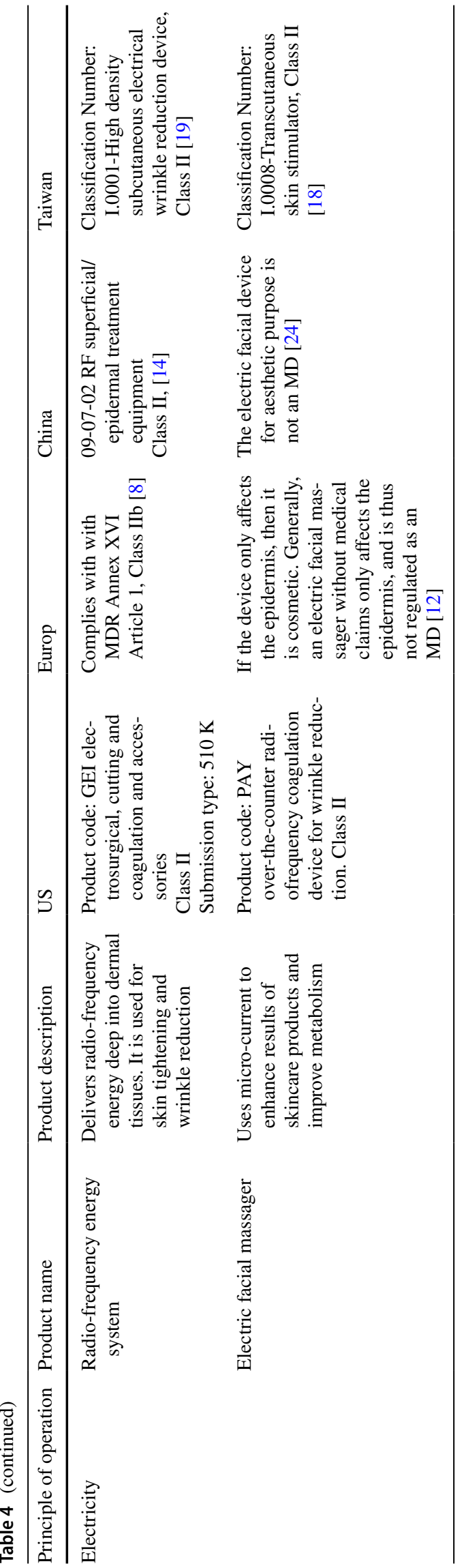

is controlled by product code 01-01-05 (Cryosurgery equipment and accessories) in the new MD list, and its risk is classified as the highest (III) [14]. For the FDA, the focused ultrasound system is controlled under product code $\mathrm{OHV}$, and $510(\mathrm{~K})$ clearance is necessary before distribution [7]. In EU, this system is classified as $\mathrm{IIb}$ according to MEDDEV 2.4/1 rev.9 [21]. In Taiwan, this system is regulated as Class II in MD classification list Classification Number I.4590- Focused ultrasound stimulator system [17].

The personal use ultrasonic facial massager claims to pass high-frequency vibration to a user's skin. This study found when massager claims to use ultrasonic or ulthera technology to achieve therapeutic effects, it would be regulated as Class II in CDRH database, and the devices would need a valid $510(\mathrm{~K})$ to be distributed in the US market [22, 23]. In EU, high-frequency vibration facial massagers are in general not MDs. For further confirmation, it needs to be evaluated case by case depending on the device's function, power, and frequency [12]. In China, according to an official document published in 2013, high-frequency vibration devices for skin improvement are not MDs [24]. In Taiwan, facial massagers using ultrasonic technology are controlled by classification number I.0008 (Transcutaneous skin stimulator) as Class II MDs [18].

\subsubsection{Optics}

A powered laser surgical instrument can be used to remove unwanted brown spots, sun freckles, or tattoos from skin. It is useful and common equipment in surgical and dermatology departments. This important medical device is classified as Class III in the China MD list. According to the classification rules of MDR (Chapter III rule 9) and a guidance document published in 2010, a laser surgical instrument is classified as Class IIb in EU [8, 21]. Both the US and Taiwan regulate laser surgical equipment as Class II [25, 26].

All light-based over-the-counter (OTC) hair removal devices need to have $510(\mathrm{k})$ clearance before they can be distributed in the US market [27]. In EU, intense pulsed light (IPL) hair removal equipment is controlled by MDR [8]. Devices that use other light sources, such as LEDs, need to evaluated case-by-case to confirm whether they comply with EU MDR. In China, IPL hair removal equipment is regulated by product code 09-03-04 [15]. In Taiwan, according to the description of classification number I.4810-laser surgical instrument for use in general and plastic surgery and in dermatology on the MD classification database, light-based over-the-counter hair removal device is classified as Class II by I.4810 [26]. 


\subsubsection{Electricity}

A radio-frequency energy system is a non-invasive device that delivers radio-frequency energy deep into dermal tissues for skin tightening and wrinkle reduction. It is a popular device in plastic surgery clinics. This machine is controlled as a Class II MD in the US, EU, China, and Taiwan [14, 19, 21, 28].

An electric facial massager uses micro-current to enhance the results of skincare products and improve metabolism. It is a popular item in online stores. In the US and Taiwan, electric facial massagers with therapeutic effects need a valid $510 \mathrm{~K}$ and need approval to be distributed in the market [18, 29]. In EU, this device is generally classified as cosmetic but this depends on the characteristics of the device [12]. In China, electric facial massagers for aesthetic purpose are not MDs [24].

According to the information presented in Table 4, the four high-end products used in clinics were all regulated as MDs in the four regions, but the four home-use products were not all listed in the authorities' MD databases.

\section{Discussion}

This study collected information from the US, EU, Chinese, and Taiwanese authorities regarding the regulations of aesthetic devices as MDs. Moreover, this study examined four clinical use products and four home-use products based on four common aesthetic application principles.

For the US and Taiwanese governments, if the working principle and intended use of the product comply with the $\mathrm{MD}$ list, the device must meet MD requirements before it can be distributed in the market. In European Union, manufactures need to follow the MDR classification rules to determine whether their device is an MD. Six aesthetic product groups are described in Article 1, Annex XVI of MDR. If a product does not belong to the six groups, the manufacture can follow the manual provided by the European Commission to determine whether the product is an MD
[12]. Chinese authority also provides an MD classification database for the industry to check whether a product is controlled as an MD. Any device that conforms to the product description in MD list is regulated as an MD. Moreover, for the devices not included in the list, the authority will make announcement irregularly to explain whether an aesthetic device is an MD. Figure 2 shows the rule to determine whether an aesthetic device is an MD. Further descriptions are as the follows.

\subsection{There is No Clearly Definition for the "Aesthetic Devices" in the Four Regions}

Although most aesthetic devices are regulated as MDs based on their technical specifications and intended use, the term "aesthetic purpose" is not included in the MD definitions in the four regions. According to the medical device definition, the product would be regulated as a medical device when it has medical purpose. However, for aesthetic devices, sometimes it is hard to determine whether the "aesthetic purpose" pertains to medical purpose; for example, colored contact lenses for changing pupil colors, and electric facial products for skin tightening and wrinkle reduction. The definition of aesthetic devices has been discussed for long time and has not got a conclusion so far. Since it is difficult to define the relationship between "aesthetic purpose" and "medical purpose", the authorities regulate the aesthetic devices based on the risk of each kind of product. In the latest MD regulation revisions of China, EU and Taiwan, several kinds of aesthetic devices have been added to the MD database and list. In particular, after discussions for long, the EU has made an amendment to list six groups of aesthetic products on the Annex XVI of MDR.

\subsection{Aesthetic Products for Personal Use are Medical Devices or Cosmetics?}

MDs and cosmetics are both regulated by food and drug administration, and each of them has clearly definition and regulation. Cosmetics are not MDs. However, different
Fig. 2 The rule to determine whether or not an aesthetic device is an $\mathrm{MD}$

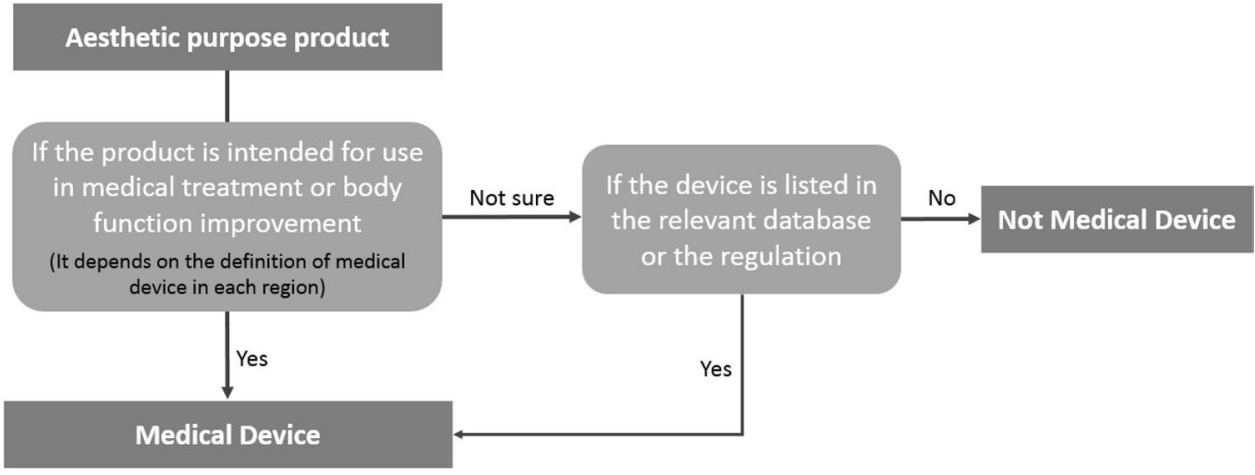


authorities have different definitions for cosmetic term. This study did not find consistent definitions for the term in the four regions. For example, electrical product for "wrinkle reduction" and "skin lifting" are generally identified as cosmetics in the EU and China, but as medical device in Taiwan. In the US, the principle of operation is also a major factor in determining whether an aesthetic device is a medical device. For example, the facial product using ionic mechanism may not be identified as an MD in the US, but it will be classified as Class II MD when the ulthera technology is used in the product.

\subsection{Challenges of Aesthetic Products for Personal Use}

Aesthetic products for personal use can be easily purchased from pharmacies and online stores. It is not easy for lay people to distinguish the differences between cosmetic and medical use. Especially, some aesthetic devices on the market are only for cosmetic purposes, but they may overstate their performance to confuse consumers. On the other hand, some devices' specification may comply with medical device, but distributed on the market as cosmetic. The problems are particularly serious for cosmetic devices for personal use. Governments have made a lot of efforts to educate the public and have demanded manufacturers to state the intended use and apply proper labels. However, this mission has to be continued. Manufacturers should also promote and label products carefully to strike a balance between user safety and commercial profitability.

\section{Conclusions}

The information collected in this study suggests that determining whether an aesthetic product is an MD on the basis of its risk could be a practical option for administrators. Even though there are no clear rules for defining the differences between "aesthetic purpose" and "medical purpose", the risk of a product could be objectively evaluated and estimated. The risk of a product is an important factor for medical device management, and thus this should be taken into consideration for making regulations.

With aesthetic medical and plastic surgery markets increasing rapidly, the demand for aesthetic devices has quickly grown. The government authorities need to make regulations keep up with new products. This study evaluated the regulation of aesthetic devices as MDs in the US, EU, China, and Taiwan. The regulation differences between high-end products and personal use products in these four markets were also examined. Although only four regions were covered in this study, the results are valuable information for improving aesthetic device management regulations.
Acknowledgements The work was supported by the Food and Drug Administration, Taiwan (Grant Number: MOHW104-FDAD-114-000503 and 107TFDA-MD-001).

\section{Compliance with Ethical Standards}

Conflict of interest All contributing authors declare no conflict of interest.

Open Access This article is distributed under the terms of the Creative Commons Attribution 4.0 International License (http://creativeco mmons.org/licenses/by/4.0/), which permits unrestricted use, distribution, and reproduction in any medium, provided you give appropriate credit to the original author(s) and the source, provide a link to the Creative Commons license, and indicate if changes were made.

\section{References}

1. International Society of Aesthetic Plastic Surgery. (2017). Global statistics worldwide summary for 2016. International Society of Aesthetic Plastic Surgery. https://www.isaps.org/wpcontent/uploads/2017/10/GlobalStatistics. WorldWide.Summa ry2016s-1.pdf. Accessed 10 July 2018.

2. International Society of Aesthetic Plastic Surgery. (2017). The international study on aesthetic/cosmetic procedures performed in 2016. https://www.isaps.org/wp-content/uploads/2017/10/ GlobalStatistics2016-1.pdf. Accessed 10 July 2018.

3. International Society of Aesthetic Plastic Surgery. (2016). ISAPS International survey on aesthetic/cosmetic procedures performed in 2015. https://www.isaps.org/wp-content/uploa ds/2017/10/2016-ISAPS-Results-1.pdf. Accessed 10 July 2018.

4. International Society of Aesthetic Plastic Surgery. (2015). ISAPS International survey on aesthetic/cosmetic procedures performed in 2014. https://www.isaps.org/wp-content/uploa ds/2017/10/2015-ISAPS-Results-1.pdf. Accessed 10 July 2018.

5. International Society of Aesthetic Plastic Surgery. (2014). ISAPS International survey on aesthetic/cosmetic procedures performed in 2013. https://www.isaps.org/wp-content/uploa ds/2017/10/2014-ISAPS-Results-3-1.pdf. Accessed 10 July 2018.

6. Grand View Research. (2016). Aesthetic medicine market size \& forecast by product type and trend analysis from 2012 to 2022 . https://www.grandviewresearch.com/industry-analysis/medicalaesthetics-market. Accessed 10 July 2018.

7. U.S. Food \& Drug Administration. Medical device product classification database. https://www.accessdata.fda.gov/scripts/cdrh/ cfdocs/cfPCD/classification.cfm. Accessed 10 July 2018.

8. European Commission. Regulation (EU) 2017/745 of the European parliament and of the council of 5 April 2017 on medical devices. https://eur-lex.europa.eu/legal-content/EN/ $\mathrm{TXT} /$ ?qid=1540174113577\&uri=CELEX:32017 R0745, Accessed 10 July 2018.

9. The Medicines and Healthcare products Regulatory Agency. (2014). Guidance on legislation: Borderlines with medical devices. https://www.gov.uk/government/publications/borderline s-with-medical-devices. Accessed 10 July 2018.

10. The Medicines and Healthcare products Regulatory Agency. (2016). Guidance on legislation: borderlines with medical devices. https://assets.publishing.service.gov.uk/government/uploads/syste m/uploads/attachment_data/file/521458/Borderlines_with_medic al_devices.pdf. Accessed 10 July 2018. 
11. European Commission. Regulation (EC) No 1223/2009 of the European Parliament and of the Council of 30 November 2009 on cosmetic products (recast). http://data.europa.eu/eli/ reg/2009/1223/2016-08-12. Accessed 10 July 2018.

12. European Commission. (2017). Manual on borderline and classification in the community regulatory framework for medical devices. http://ec.europa.eu/DocsRoom/documents/26785/attac hments/1/translations. Accessed 10 July 2018.

13. The People's Republic of China. (2014). Order of the state council, No. 650 Article 76: Regulation on the supervision and administration of medical devices.

14. China Food \& Drug Administration. (2018). Official announcement No. 104 of 2017: Medical device classification catalog.

15. China Food \& Drug Administration. (2018). Official announcement No. 10 of 2018: Product classification notice.

16. Taiwan Ministry of Health and Welfare. (2013). Pharmaceutical affairs law article 13. Retrieved July 10, 2018 from https://www. mohw.gov.tw. Accessed 10 July 2018.

17. Taiwan Ministry of Health and Welfare. Annex I of the regulations for governing the management of medical device: Medical device classification catalog, amended on 25 July 2017. https:// law.moj.gov.tw/Eng/LawClass/LawContent.aspx?PCODE=L0030 054. Accessed 10 July 2018.

18. Taiwan Ministry of Health and Welfare. Medical device classification database, classification number I.0008. http://mdlicense.itri. org.tw/DB/MDClassificationContent.aspx?id=I.0008. Accessed 10 July 2018.

19. Taiwan Ministry of Health and Welfare. Medical device classification database, classification number I.0001. http://mdlicense.itri. org.tw/DB/MDClassificationContent.aspx?id=I.0001. Accessed 10 July 2018.

20. Taiwan Ministry of Health and Welfare. Medical device classification database, classification number O.5525. http://mdlicense.itri.
org.tw/DB/MDClassificationContent.aspx?id=O.5525. Accessed 20 October 2018.

21. European Commission. Medical devices: Guidance documentclassification of medical devices, 2010.

22. U.S. Food \& Drug Administration. Medical device product classification database, product code IMI. https://www.accessdata .fda.gov/scripts/cdrh/cfdocs/cfPCD/classification.cfm?ID=5042. Accessed 20 October 2018.

23. U.S. Food \& Drug Administration. (2018). Import alert 89-08. https://www.accessdata.fda.gov/cms_ia/importalert_244.html. Accessed 10 July 2018.

24. China Food \& Drug Administration. Official announcement No. 31 of 2013: Product classification notice.

25. U.S. Food \& Drug Administration. Medical device product classification database, product code GEX. https://www.accessdata .fda.gov/scripts/cdrh/cfdocs/cfPCD/classification.cfm?id=5601. Accessed 10 July 2018.

26. Taiwan Ministry of Health and Welfare. Medical device classification database, classification number I.4810. http://mdlicense.itri. org.tw/DB/MDClassificationContent.aspx?id=I.4810. Accessed 10 July 2018.

27. U.S. Food \& Drug Administration. Medical device product classification database, product code OHT. https://www.accessdata .fda.gov/scripts/cdrh/cfdocs/cfPCD/classification.cfm?id=5746. Accessed 10 July 2018.

28. U.S. Food \& Drug Administration. Medical device product classification database, product code GEI. https://www.accessdata .fda.gov/scripts/cdrh/cfdocs/cfPCD/classification.cfm?id=5595. Accessed 10 July 2018.

29. U.S. Food \& Drug Administration. Medical device product classification database, product code PAY. https://www.accessdata .fda.gov/scripts/cdrh/cfdocs/cfPCD/classification.cfm?id=5801. Accessed 10 July 2018. 